\title{
PRODUCTION OF OYSTER MUSHROOM ON DIFFERENT SUBSTRATES USING CYLINDRICAL BLOCK SYSTEM
}

\author{
R. C. Dey, K. M. Nasiruddin, M. S. Haque and M. A. Z. Al Munsur \\ Department of Biotechnology, Bangladesh Agricultural University \\ Mymensingh-2202, Bangladesh
}

\begin{abstract}
The experiments were conducted at the Mushroom and Tissue Culture Laboratory, Horticulture Demonstration and Training Center (HDTC), DAE, Keyotkhali, Mymensingh during the period from February to May 2006. Oyster mushroom was cultivated on different substrates viz. paddy straw, sugarcane bagasse and mustard straw using cylindrical block system to find out suitable substrate. Different substrates significantly affected the number of primordia and fruiting bodies, and the amount of fresh weight or yield of Oyster mushroom in cylindrical block system. The highest number of primordia and fruiting bodies, and the amount of fresh weight was obtained with sugarcane bagasse in all flushes whereas, the lowest with mustard straw.
\end{abstract}

Key words : Cylindrical block system, Oyster mushroom, Production, Substrates

\section{INTRODUCTION}

Mushroom was belonging to the kingdom Fungi under the Basidomycota due to unique fungal characteristics (Song, 2004). Mushrooms are being used as food and medicine since time immemorial. According to Chang (1992) the protein value of dried mushroom has been found to be $30-40 \%$ containing all the essential amino acids. Mushrooms constitute an ideal source to reduce body weight. Mushrooms supply more protein per unit area than other crops (Gupta, 1986). Mushroom helps to reduce serum cholesterol and high blood pressure (Mori et al., 1986). Ganoderma lucidum is renowned for its medicinal properties (Willard, 1990) and often is associated with health and repercussion, longevity, wisdom, and happiness (Stamets, 1990). In Bangladesh, huge amount of agricultural wastes are produced annually, and are of no uses. These wastes could be used as source of food i.e. substrate for mushroom cultivation. Al Amin (2004) in his experiment revealed that the highest number of primordia and fruiting bodies of Oyster mushroom was found in sterilized paddy straw. Maniruzzaman (2004) in his study found that substrate rice was the best for spawn production of Oyster mushroom. Oyster mushroom (locally known as dhingri) is easy to grow comparatively in tropical and subtropical climate. These species are characterized by the rapidity of their mycelial proliferation. There is no need of composting of substrate for Oyster mushroom production. Oyster mushrooms are easily dried to provide for a longer shelf life and export possibilities. To make Oyster mushroom cultivation more profitable and popular, different types of agrowastes, crop residues and byproducts can be used with cylindrical block system, which has already been proven economically viable rather than conventional polybag method. 
However, a profitable mushroom cultivation on large scale also requires close attention, experience and skill (Carluccio, 1989). Therefore, three experiments were carried out at production of Oyster mushroom on different substrates using cylindrical block system.

\section{MATERIALS AND METHODS}

The methodology that was used in these experiments was standardized following the methods of Siddiqui (2002).

\section{Preparation of substrate for spawn production}

For the preparation of substrate for spawn production wheat were washed, dried and boiled separately for 50 minutes and again dried in air by spreading on polythene sheet to remove surface moisture. After that $2 \% \mathrm{CaCO}_{3}$ and $1 \%$ chalk powder were mixed thoroughly on the polythene sheet. Then $250 \mathrm{~g}$ substrate were taken in to each polypropylene bag and plugged with cotton and rubber band.

\section{Preparation of substrate}

For the preparation of paddy, mustard straw and sugarcane bagasse chopped $(2.54 \mathrm{~cm}$ size) and dry these substrates was soaked in water for about 24 hours to get wet and achieved $65-70 \%$ of moisture content The next day, all these wet substrates were separated from water and excess water was removed properly. Then all these substrates were chopped and boiled for 1 hour. After cooling, the pasteurized substrates were kept on the concrete floor and limed with $10 \% \mathrm{CaCO}_{3}$ solution. Then rice bran, gypsum and molasses were mixed with the pasteurized paddy mustard straw and rice bran \& gypsum with the sugarcane bagasse. The substrates were thus ready to be used in mushroom cultivation.

\section{Culture method}

Three big polypropylene bags full of each type of substrates were placed in cylindrical block device. At first, a layer of prepared substrate was taken into a big polypropylene bag and then about $50 \mathrm{~g}$ of previously prepared spawn was spreaded on the outer side of substrate with cautions. This spawning process was repeated several times in the same manner. But last layer of spawn was covered with less amount of substrate. Then the bags were packed tightly and kept on cylindrical block device.

All instruments, glasswares and culture media were sterilized by autoclaving with 15 PSI at $121^{\circ} \mathrm{C}$ for $1-2$ hours. The culture room of the laboratory was cleaned by gently washing with detergent followed by $70 \%$ ethyl alcohol regularly.

Data were recorded periodically during the growing season namely- $1^{\text {st }}$ flush, $2^{\text {nd }}$ flush and $3^{\text {rd }}$ flush. The observations were recorded on the number of primordia, fruiting bodies and fresh weight of mushroom. The data were statistically analyzed following the Randomized Complete Block Design (RCBD) and means were compared following 
Duncan's Multiple Range Test (DMRT) test at 5\% level of probability for interpretation of results (Gomez and Gomez, 1984).

\section{RESULTS AND DISCUSSION}

\section{Number of primordia}

In the first flush, the number of primordia was found with significant variation in all substrates. The highest number of primordia (222.3) was found in sugarcane bagase and the lowest (170.3) in mustard straw (Table 1). The similar trends were also observed in the $2^{\text {nd }}$ and $3^{\text {rd }}$ flush (Table 2 and 3 ).

\section{Number of fruiting bodies}

The highest number of fruiting bodies (234.7) of Oyster mushroom was found in sugarcane bagasse and the lowest (179.7) in mustard straw in the $1^{\text {st }}$ flush (Table 1 and Plate 2 and 1). The number of fruiting bodies was found to vary significantly among all substrates. The similar trends were also observed in the $2^{\text {nd }}$ and $3^{\text {rd }}$ flush (Table 2 and 3 ). Haque (2004) found the highest number of fruiting bodies in non sterilized paddy straw through polypropylene bag system and Al Amin (2004) found the highest fruiting bodies in paddy straw also with same system.

\section{Fresh weight of fruiting bodies}

The highest (1029.0 g) fresh weight of fruiting bodies was obtained in sugarcane bagasse, whereas the lowest $(943.7 \mathrm{~g})$ in mustard straw (Table 1). These results were found statistically different in different substrates. The similar trends were also observed in the $2^{\text {nd }}$ and $3^{\text {rd }}$ flush (Table 2 and 3 ).

Table 1. Effect of different substrates on yield of Oyster mushroom (First flush)

\begin{tabular}{l|cc|c}
\hline \multicolumn{1}{c}{ Substrate } & No. of primordia & No. of fruiting bodies & Fresh weight of fruiting bodies $(\mathrm{g})$ \\
\hline Paddy straw & $196.3 \mathrm{~b}$ & $206.7 \mathrm{~b}$ & $987.0 \mathrm{~b}$ \\
Sugarcane bagasse & $\mathbf{2 2 2 . 3 ~ a}$ & $\mathbf{2 3 4 . 7 ~ a ~}$ & $\mathbf{1 0 2 9 . 0 ~ a}$ \\
Mustard straw & $170.3 \mathrm{C}$ & $179.7 \mathrm{c}$ & $943.7 \mathrm{C}$ \\
\hline \multicolumn{1}{c}{ CV\% } & 5.71 & 5.64 & 2.79 \\
\hline
\end{tabular}

In a column, figures followed by common letter (s) do not differ significantly at the level of $5 \%$ probability as per DMRT

Table 2. Effect of different substrates on yield of Oyster mushroom (Second flush)

\begin{tabular}{|c|c|c|c|}
\hline Substrate & No. of primordia & No. of fruiting bodies & Fresh weight of fruiting bodies $(\mathrm{g})$ \\
\hline Paddy straw & $209 \mathrm{~b}$ & $221.7 \mathrm{~b}$ & $1187 \mathrm{~b}$ \\
\hline Sugarcane bagasse & 239 a & 249.7 a & 1229 a \\
\hline Mustard straw & $182 \mathrm{c}$ & $194.7 \mathrm{c}$ & $1144 \mathrm{c}$ \\
\hline $\mathrm{CV} \%$ & 5.57 & 5.26 & 1.51 \\
\hline
\end{tabular}

In a column, figures followed by common letter (s) do not differ significantly at the level of $5 \%$ probability as per DMRT 
Table 3. Effect of different substrates on yield of Oyster mushroom (Third flush)

\begin{tabular}{l|cc|c}
\hline \multicolumn{1}{c|}{ Substrate } & No. of primordia & No. of fruiting bodies & Fresh weight of fruiting bodies (g) \\
\hline Paddy straw & $140.7 \mathrm{~b}$ & $150.3 \mathrm{~b}$ & $786.0 \mathrm{~b}$ \\
Sugarcane bagasse & $\mathbf{1 6 0 . 7} \mathbf{~ a}$ & $\mathbf{1 7 0 . 7 ~ a}$ & $\mathbf{8 2 8 . 0 ~ a ~}$ \\
Mustard straw & $121.3 \mathrm{C}$ & $131.7 \mathrm{c}$ & $742.7 \mathrm{c}$ \\
\hline \multicolumn{1}{c}{ CV\% } & 5.92 & 5.38 & 2.25 \\
\hline
\end{tabular}

In a column, figures followed by common letter (s) do not differ significantly at the level of $5 \%$ probability as per DMRT

Sugarcane bagasse gave maximum number of primordia and fruiting bodies, and fresh weight followed by rice straw and the lowest in mustard straw. The yield difference was significant in this experiment. The variations were probably occurred due to the difference of bulk density and constituents of the substrates used. Sivaprakasam (1986) found that the yield of mushroom was correlated positively with cellulose content and cellulose: lignin ratio, but negatively with lignin and ortho-dihydroxy phenolics content. Quimio (1987) stated that cellulose rich organic substance has been reported to be of good substrates for the cultivation of mushrooms. Substrates with high lignin and phenolic content decreased the activity of cellulase, but less lignin would enhance enzyme activity and thus ensure higher yield of mushrooms (Sivaprakasam, 1980).

From the above study we found that, sugarcane bagasse performed best followed by rice straw and mustard straw for the production of Oyster mushroom using cylindrical block system.

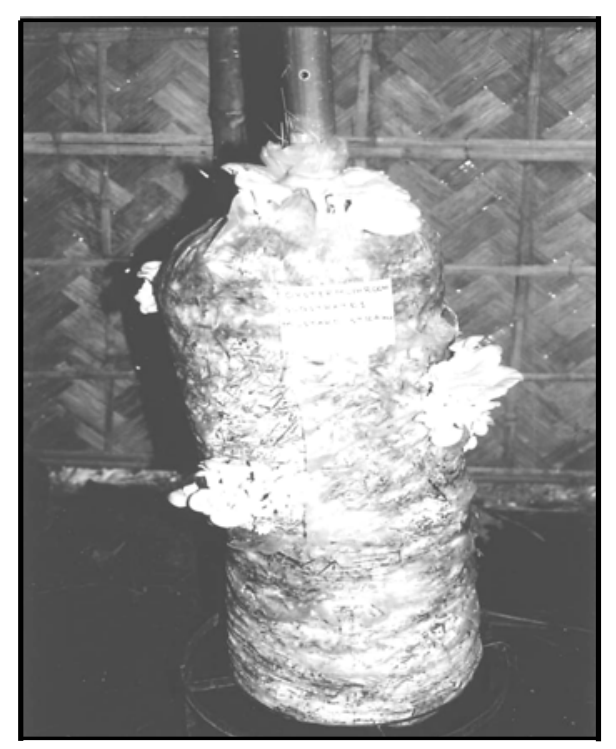

Plate 1. Fruiting bodies of Oyster mushroom developed on mustard straw at first flush

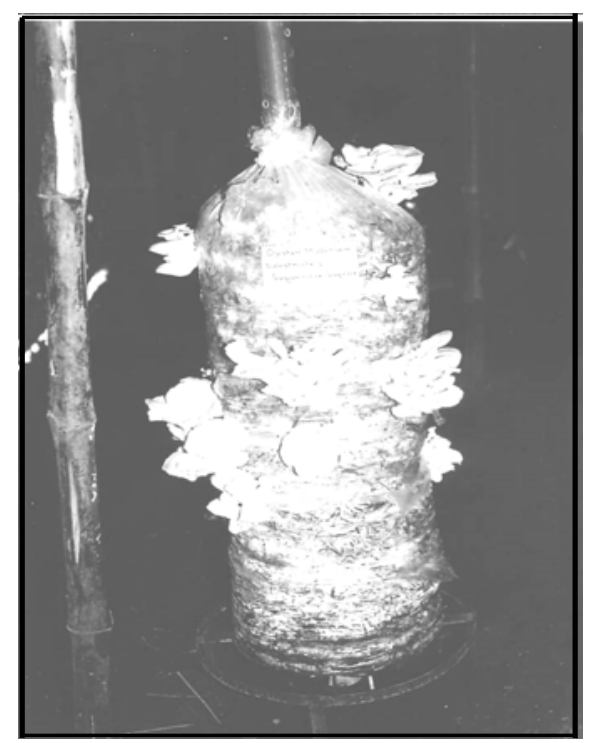

Plate 2. Fruiting bodies of Oyster mushroom developed on sugarcane bagasse at first flush 


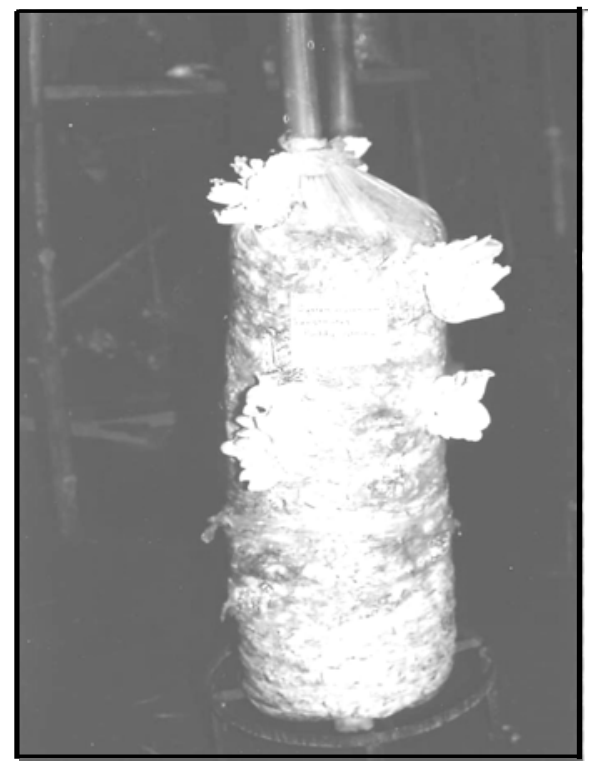

Plate 3. Fruiting bodies of Oyster mushroom developed on paddy straw at first flush

\section{REFERENCES}

Al Amin, M. A. 2004. Studies on mycelium, spawn and production of certain edible mushrooms. M. S. Thesis, Department of Biotechnology, Bangladesh Agricultural University, Mymensingh, Bangladesh.

Carluccio, A. 1989. A Passion for Mushrooms. Pavillion Books Ltd, London.

Chang, S. T. 1992. Cultivation of Volvariella Mushrooms in Southeast Asia, In: Trop. Mushrooms; Biological Nature and Cultivation Methods. The Chinese Univ. Press, Hong Kong. pp. 135-156.

Gomez, A. C. and Gomez, A. A. 1984. Statistical Procedures for Agricultural Research (2 ${ }^{\text {nd }}$ Edn.). John Wiley and Sons, New York. p. 680.

Gupta, R. S. 1986. Mushroom Cultivation. Indian Hort., 31(1): 11.

Haque, A. B. M. A. 2004. Use of different substrates and methods on the mycelial growth, spawn production and yield of three mushroom species. M. S. Thesis, Department of Biotechnology, Bangladesh Agricultural University, Mymensingh, Bangladesh.

Maniruzzaman, M. 2004. Influence of media composition and growth regulators on mycelial growth and spawn production of three mushroom species. M. S. Thesis, Department of Biotechnology, Bangladesh Agricultural University, Mymensingh, Bangladesh.

Mori, K., Toyomasu, T., Nanba, H. and Kuroda, H. 1986. Antitumor Activities of Edible Mushrooms By Oral Administration. Proc. Int'1. Sym. Sci. Tech. Aspect of Culti. Edible Fungi. Penna. State Univ. USA. pp. 49-55.

Quimio, T. H. 1987. Introducing Pleurotus flabellatus for your dinner table. The mushroom Journal, 96: 282-283 
Siddiqui, A. B. 2002. Mushroom Production Technology. IHAND project, GOB/UNDP/ FAO, Rangdhanu Printers, pp. 1-14.

Sivaprakasam, K. 1980. Studies on Oyster mushroom (Pleurotus sajor-caju) Fr. Ph. D. Thesis, Tamil Nadu Agril. Univ., Coimbatore, India

Sivaprakasam, K. 1986. Constituents of substrates in relation to sporophore yield of Pleurotus sajor-caju Fr. Madras J. Agril., 73(11): 601-605

Song, B. C. 2004. Oyster Mushroom Cultivation. Mushroom Growers' Handbook 1 www. Mush-World_Com.htm

Stamets, P. 1990. A discussion on the cultivation of Ganoderma lucidum (Curtis: Fr.) Kar. The reishi of ling zhi mushroom of mortality. Mcllvainea., 9(2): 40-50.

Willard, T. 1990. Reishi mushroom: Herb of spiritual potency and medical wonder. Sylvan Press, Issaquah, W.A. pp.238-249 